\title{
Editorial
}

\section{Invitation and a Warm Welcome to the 41th Annual Meeting of the Society for Neuropediatrics}

\author{
Peter Weber $^{1}$ \\ ${ }^{1}$ Divison of Neuropediatrics and Developmental Medicine, University \\ Children's Hospital Basel, Switzerland \\ Neuropediatrics 2015;46:77.
}

With great pleasure, we invite you to join us this year at the 41th Annual Meeting of the Society for Neuropediatrics in Basel. In the period of past 25 years, since the last meeting of our society in Basel, numerous fascinating neuroscientific basic and clinical research findings augmented our pathophysiological understanding of different neurological diseases and the diagnostic and therapeutic options. However, the more complex comprehension of diseases and the new technologies require a growing multidisciplinary and teambased working. Therefore, in our meeting, which will take place from April 23 to 26, 2015, at the Congress Center Basel (http://neuropaediatrie-congress.de/GNP2015/) the aspects of networking in the field of pediatric neurology will be focus.

Through lectures, symposia, practical workshops, free talks, and posters, we put forward recent trends and knowledge regarding the main topics of our congress, which are spinal diseases, congenital myopathies, developmental neurology, language, intellectual disability, and somatoform disorders. Special sessions about different interventions to decrease spasticity or special therapeutic questions bring together child neurologists and therapists and will increase the productive discussion.

A highlight of this meeting will be the Peter-Emil-BeckerPrice Award lecture by Prof Linda DeVries, from the University Medical Center of Utrecht, to honor her longstanding and excellent scientific work in the field of neonatal neurology, especially using different neuroimaging techniques and her pioneering work to introduce continuous amplitude integrated electroencephalography in the diagnostic work-up in neonatal units.

Also this year the award of the DESITIN-Jungforscherpreis will be one of the further highlights of our meeting. Dr Franziska Hoche will give her lecture about "Cognitive phenotype in Ataxia-Telangiectasia," an example for a very successful translational scientific work.

Of course, in the face with all these intellectual stimulation, we will need some social contacts and relaxing moments during a networking dinner and taking a drink at the waterfront of the Rhine, which should increase the contact in our society between experienced experts and young colleagues, basic researchers, and clinical neurologists and between neurologists and therapists. Basel as a historical city of humanism located in the heart of Europe and in an idyllic border triangle of France, Germany, and Switzerland is the ideal location to achieve these aims.

The abstracts of the talks and posters will be published as an online-only supplement to Neuropediatrics. The link to this supplement will be posted later on the homepage of our society, www.neuropaediatrie.com.

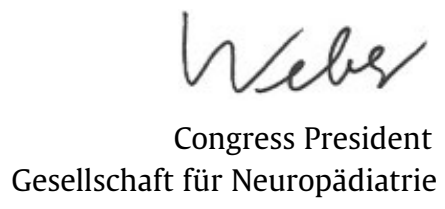

(c) 2015 Georg Thieme Verlag KG Stuttgart · New York
DOI http://dx.doi.org/ ISSN 0174-304X. $10.1055 / \mathrm{s}-0035-1547343$. 